\title{
An Anomalous Case of the Hepato-spleno-mesenteric and the Gastro-phrenic Trunks Independently Arising from the Abdominal Aorta
}

\author{
YOSHIMASA HIRAI*,**, KOH-ICHI YAMAKI*, TSUYOSHI SAGA*, TETSUSHI HIRATA ${ }^{\dagger}$, \\ MINAKO YOSHIDA*, HIROKO SOEJIMA*‡, TAKETOSHI KANAZAWA*,**, \\ YOSHIO ARAKI* AND MITSUAKI YOSHIZUKA* \\ Departments of Anatomy*, Orthopaedic Surgery **, and Pediatric Surgery ${ }^{\ddagger}$, Kurume University \\ School of Medicine, Kurume 830-0011 and 'Department of Health and Physical Education, \\ Fukuoka University of Education, Munakata 811-4192, Japan
}

\begin{abstract}
Summary: This report describes an arterial anomaly case in the celiaco-mesenteric region, which was encountered in a Japanese male cadaver in the dissecting room at Kurume University School of Medicine in 1999. In this case, the usual celiac trunk was not identified, and the hepato-splenomesenteric and the gastro-phrenic trunks were independently arising from the abdominal aorta. In addition, the common hepatic artery divided into the left hepatic, the right hepatic, and the gastroduodenal arteries simultaneously, then, the accessory gastric artery arose from the left hepatic artery. This type of arteral anomaly belongs to the Type III of Adachi's classification and the Type II" of Morita's classification.
\end{abstract}

Key words human anatomy, arterial anomaly, hepato-spleno-mesenteric trunk, gastro-phrenic trunk, accessory gastric artery

\section{INTRODUCTION}

During the gross anatomy course at Kurume University School of Medicine in 1999, a rare arterial anomaly of the hepato-spleno-mesenteric and the gastro-phrenic trunks independently arising from the abdominal aorta was found.

Since a knowledge of the distribution of the celiac trunk and the superior mesenteric artery is essential for medical practice, numerous reports of vascular variations in this region have been published [1-6]. However, the case reports of this type of arterial anomaly are few. Therefore, a detailed morphology of the present case is described in this report. The etiology of this type of vascular anomaly is also discussed.

\section{CASE REPORT}

This report describes the arterial anomaly, which was found in a 74-year-old Japanese male. In this case, the usual celiac trunk was not identified, and the hepato-spleno-mesenteric trunk and the gastrophrenic trunk independently originated from the abdominal aorta. Moreover, there was no hepatic proper artery and the accessory gastric artery arose from the left hepatic artery.

Photographs of this case are shown in Fig. 1 and illustrated schematically in Fig. 2.

\section{The abdominal aorta}

The abdominal aorta followed a fundamentally normal course. At the level of the twelfth thoracic vertebra, the gastro-phrenic trunk arose from the left side of the anterolateral wall of the abdominal aorta. The hepato-spleno-mesenteric trunk arose from the anterior wall of the abdominal aorta at the first lumbar vertebra, which was approximately $19.2 \mathrm{~mm}$ distal to the origin of the gastro-phrenic trunk. 

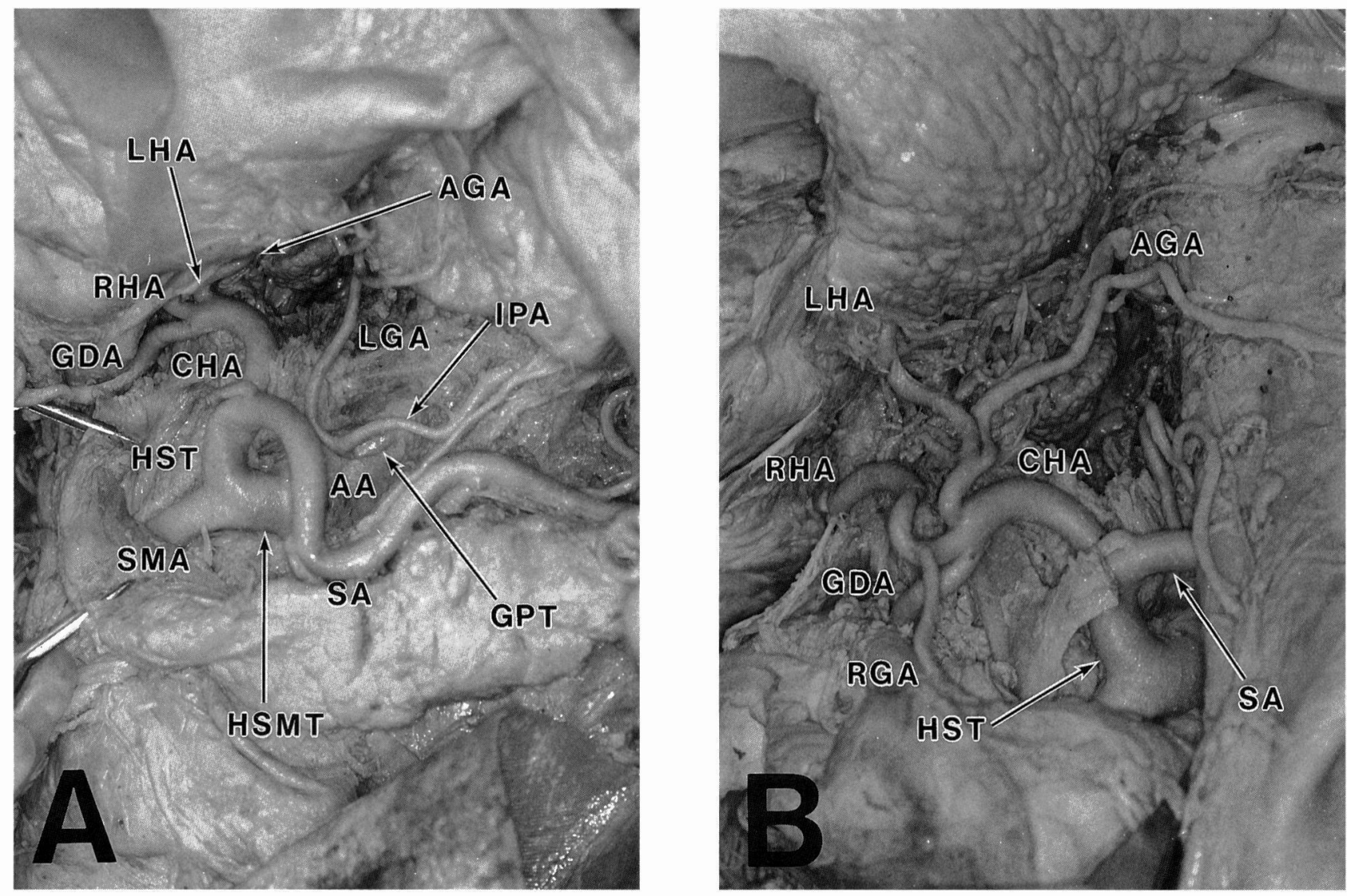

Fig. 1A, B. A photograph showing a general view of the present case. AA: abdominal aorta; GPT: gastro-phrenic trunk; LGA: left gastric artery; IPA: inferior phrenic artery; HSMT: hepato-spleno-mesenteric trunk; HST: hepatosplenic trunk; CHA: common hepatic artery; SA: splenic artery; SMA: superior mesenteric artery; LHA: left hepatic artery; RHA: right hepatic artery; GDA: gastroduodenal artery; RGA: right gastric artery; AGA: accessory gastric artery

\section{The gastro-phrenic trunk}

The external diameter was approximately $3.4 \mathrm{~mm}$ at its origin. It ran downward anteriorly for approximately $10.5 \mathrm{~mm}$, it divided into the inferior phrenic artery and the left gastric artery. Then, the inferior phrenic artery divided into the right and the left inferior phrenic arteries. The external diameter of the inferior phrenic artery was approximately $3.1 \mathrm{~mm}$ at its origin, and that of the left gastric artery was approximately $3.0 \mathrm{~mm}$ at its origin. The left gastric artery ran laterally to reach the lesser curvature of the stomach and divided into the anterior and posterior branches. The posterior branch gave off the esophageal artery.

\section{The hepato-spleno-mesenteric trunk}

The external diameter of this trunk was approximately $12.7 \mathrm{~mm}$ at its origin. It ran anteriorly for approximately $13.1 \mathrm{~mm}$ and divided into the hepatosplenic trunk (the external diameter was approximate- ly $8.4 \mathrm{~mm}$ at its origin) and the superior mesenteric artery (the external diameter was approximately 7.6 $\mathrm{mm}$ at its origin). The hepato-splenic trunk ran superiorly for approximately $13.8 \mathrm{~mm}$ and divided into the common hepatic artery (the external diameter was approximately $5.6 \mathrm{~mm}$ at its origin) and the splenic artery (the external diameter was approximately $6.2 \mathrm{~mm}$ at its origin).

Then, the common hepatic artery ran laterally for approximately $28.8 \mathrm{~mm}$ and divided into the left hepatic artery (the external diameter was approximately $3.7 \mathrm{~mm}$ at its origin), the right hepatic artery (the external diameter was approximately $4.0 \mathrm{~mm}$ at its origin), and the gastroduodenal artery (the external diameter was approximately $4.0 \mathrm{~mm}$ at its origin), simultaneously. The hepatic proper artery was not existed in this case. The right gastric artery arose from the right hepatic artery approximately $4.0 \mathrm{~mm}$ distal to the origin of this artery. The external diameter of the right gastric artery was approximately 2.0 


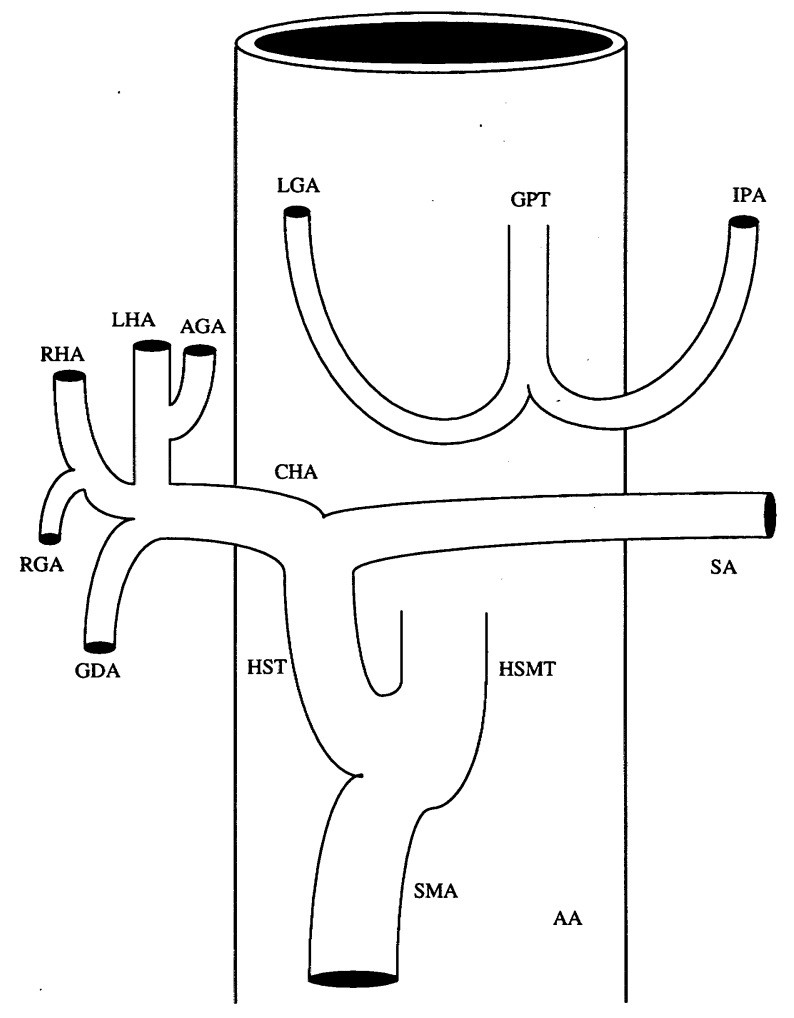

Fig. 2. A schematic illustration of Fig. 1. AA: abdominal aorta; GPT: gastro-phrenic trunk; LGA: left gastric artery; IPA: left inferior phrenic artery; HSMT: hepato-spleno-mesenteric trunk; HST: hepato-splenic trunk; CHA: common hepatic artery; SA: splenic artery; SMA: superior mesenteric artery; LHA: left hepatic artery; RHA: right hepatic artery; GDA: gastroduodenal artery; RGA: right gastric artery; AGA: accessory gastric artery

$\mathrm{mm}$ at its origin. Moreover, approximately $11.1 \mathrm{~mm}$ distal to the origin of the left hepatic artery, the accessory gastric artery arose from this artery. The external diameter of this artery was approximately $2.7 \mathrm{~mm}$ at its origin. The accessory gastric artery ran laterally to the left and distributed to the posterior wall of the fundus and cardiac region of the stomach.

\section{DISCUSSION}

With regard to the morphogenesis of the celiac trunk and the superior mesenteric artery, Tandler [7] proposed the following hypothesis. He stated that, 4 primitive splanchnic branches arise from the abdominal aorta in early phase of human embryogenesis, and these branches are connected to the ventral longi- tudinal anastomotic channels. Retention or disappearance of parts of this primitive arterial plexus could give rise to numerous anomalous variations of the celiac trunk and the superior mesenteric artery. On the basis of this description, Morita [8] classified the variational patterns of these arteries, and suggested 5 types and 15 forms (Fig. 3). According to this classification, the present case belongs to the Type II'. It seems likely that, in this type, the first ventral splanchnic branch formed the left gastric artery, while the fourth ventral splanchnic branch might form the hepato-spleno-mesenteric trunk by fusion among the hepatic, the splenic, and the superior mesenteric arteries via the secondary ventral longitudinal anastomosis.

The reports of the Type II' anomaly are relatively few. Only 5 case reports appear in European literature $[7,9,10]$, and 11 cases have been reported in Japan [11-17]. Estimated frequency was reported between $0.0 \%$ [18] and $1.2 \%$ [11]. In our laboratory, the present case is the fifth case of this kind of anomaly, which was found from 1990 to 1999 . Then, the frequency was $1.33 \%$ ( 5 cases out of 377 cadavers).

In 1928, Adachi [11] also proposed the detailed classification of this region. He defined the left gastric, splenic, common hepatic, and superior mesenteric arteries as the principal branches in this region, moreover, took into consideration the existence of the accessory hepatic and gastric arteries, and classified the distribution pattern of these arteries into 6 types with 28 forms. According to this classification, the arterial anomaly of the left gastric artery and the hepato-spleno-mesenteric trunk independently arising from the abdominal aorta as in the present case belongs to the Type III. This type is equal to the Type II' of Morita's classification. However, Adachi described that the Type III anomaly could subdivide into 2 different forms, namely groups 18 and 19. Group 18 has no accessory arteries, and group 19 has the accessory hepatic artery. The above mentioned previously reported 7 cases and another 4 cases, which were previously found in our laboratory, had no accessory arteries, therefore, they belonged to the Type III group 18. Another 9 cases had the accessory hepatic arteries but no accessory gastric artery. In our present case, the accessory gastric artery arose from the left hepatic artery. We consider that this is the first case report of the Type III arterial anomaly of Adachi's classification with the accessory gastric artery. 

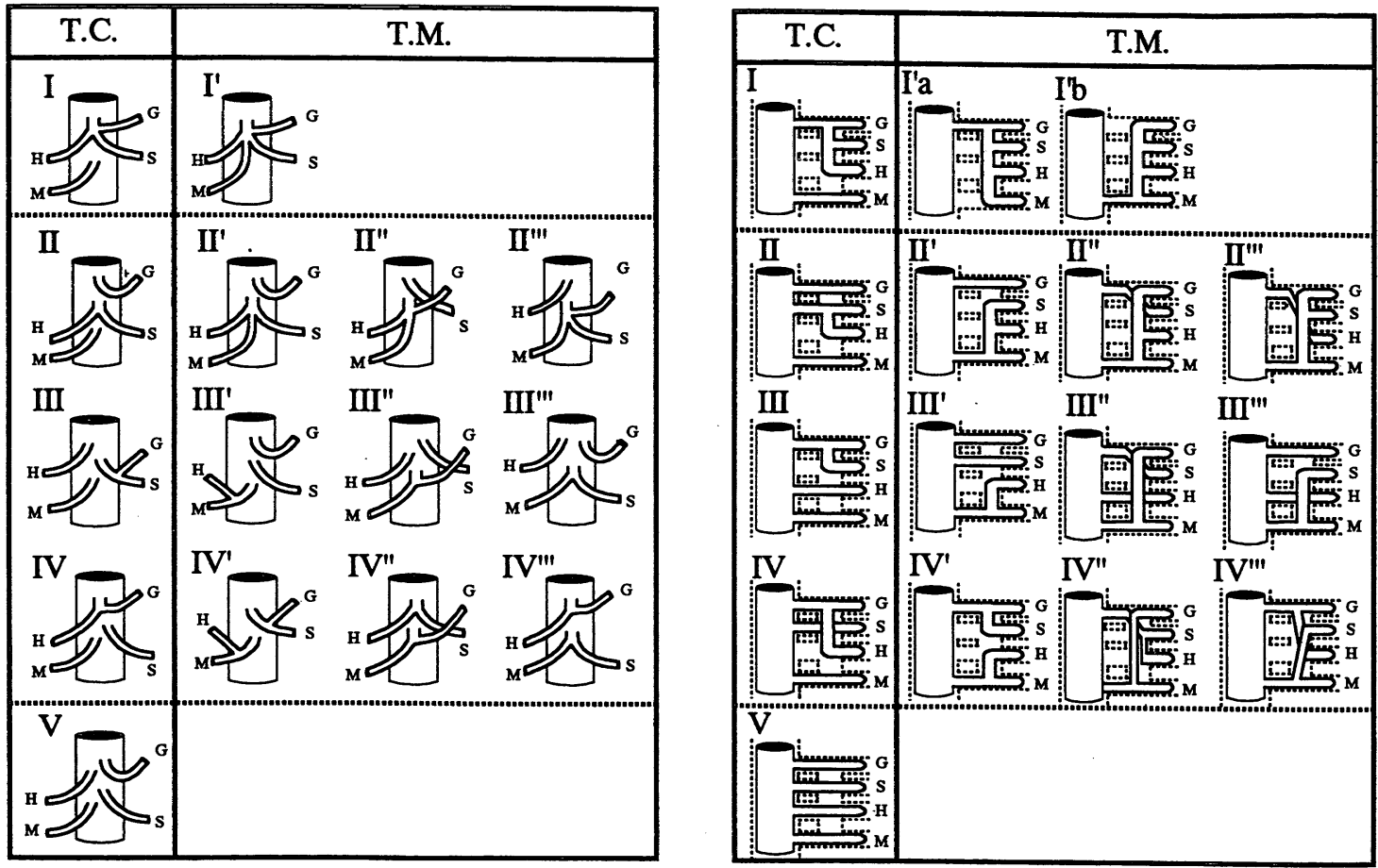

Fig. 3. Diagrams showing a variety of arrangements of origin of the celiac trunk and the superior mesenteric artery, based on Morita's classification (1935).

T.C.: Typus celiacus; T.M.: Typus celiaco-mesentericus; G: left gastric artery; S: splenic artery; H: common hepatic artery; M: superior mesenteric artery

\section{REFERENCES}

1. Lippert $\mathrm{H}$, and Pabst $\mathrm{R}$. Arterial variations in man: Classification and frequency. JF Bergmann Verlag München, München, 1985.

2. Yamaki K, Tanaka N, Matsushima T, Miyazaki K, and Yoshizuka M. A rare anomalous case of the absence of the celiac trunk: the left gastric, the splenic, the common hepatic and the superior mesenteric arteries arising independently from the abdominal aorta. Ann Anat 1995; 177:97-100

3. Noah EM, Klinzing S, Zwaan M, Schramm U, Bruch HP et al. Normvarianten der arteriellen Leberversorgung in Mesenterico-Coeliacographien. Ann Anat 1995; 177:305312.

4. Harada H, Yamaki K, Doi Y, Saga T, Sannomiya T et al. An anomalous case of the gastro-splenic and the hepatomesenteric trunks independently arising from the abdominal aorta. Kurume Med J 1996; 43:181-184.

5. Harada H, Yamaki K, Doi Y, Hirata T, Saga T et al. An anomalous case of the gastro-hepatic and the splenomesenteric trunks independently arising from the abdominal aorta. Kurume Med J 1997; 44:237-240.

6. Harada H. An anatomical study on the branches of the celiac trunk and the superior mesenteric artery. J Kurume Med Assoc 1997; 60:372-381. (in Japanese)

7. Tandler J. Über die Varietäten der Arteria coeliaca und deren Entwicklung. Anat Hefte 1904; 25:473-500.

8. Morita M. Reports and conception of three anomalous cases in the area of the celiac and the superior mesenteric arteries. Igaku Kenkyu 1935; 9:1993-2006. (in Japanese)

9. Clausen HJ. An unusual variation in origin of the hepatic and splenic arteries. Anat Rec 1955; 123:335-340.

10. Michels NA. Blood supply and anatomy of the upper abdominal organs with a descriptive atlas. Lippincott, Philadelphia, 1955.

11. Adachi B. Das Arteriensystem der Japaner. Bd 1. Die Kaiserlich Japanische Universität zu Kyoto, Kyoto, 1928.

12. Morita M. Three anomalous cases of the celiac trunk Igaku Kenkyu 1936; 10:473-478. (in Japanese)

13. Imakoshi K. A study on the celiac artery. Kanazawa Ikadaigaku Kaibougakukyositsu Gyosekishu 1949; 37:114. (in Japanese)

14. Minooka M. Anatomical and anthropological studies on the celiac axis and its branches of the Ainu. Sapporo Ishi 1975; 44:41-60. (in Japanese)

15. Higashi $\mathrm{N}$, and Sone $\mathrm{C}$. Two anatomical cases of truncus celiacus. Acta Anat Nippon 1986; 61:709-715. (in Japanese)

16. Ouchi $\mathrm{H}$, and Katoh N. Four anomalous cases of the Trunkus celiacus. Okayama Ishi 1961; 73:25. (in Japanese) (quoted from Higashi and Sone)

17. Yamahira T. Anatomical and statistical study on the branches of the celiac trunk. Acta Sch Med Univ Gihu 1993; 41:43-71. (in Japanese)

18. Van Damme JP, and Bonte J. Vascular anatomy in abdominal surgery. Thieme, Stuttgart-New York, 1990. 